J Chron Dis 1973, Vol. 26, pp. 699-717. Pergamon Press. Printed in Great Britain

\title{
THE IMPORTANCE OF AGE EFFECTS ON PERFORMANCE IN THE ASSESSMENT OF CLINICAL TRIALS*
}

\author{
A. R. Potvin†, W. W. Tourtellotte $\ddagger$, R. W. Pew\$, J. W. Albers!, \\ W. G. Henderson** and D. N. SNYDER ${ }^{*} \dagger$
}

The Bioengineering Program and the Departments of Neurology and Psychology, The University of Michigan, Ann Arbor, Michigan, U.S.A.

(Received 23 January 1973; in final form 30 May 1973)

\section{INTRODUCTION}

DURING the past decade, a large battery of performance tests called the Quantitative Examination of Neurological Function (QENF) has been assembled [1-4]. A summary description of the tests in the battery has been published [4, 5]. Recently, the test battery has been used to evaluate clinical drug trials [5-7].

The present study, designed to objectively evaluate certain measurement procedures, is concerned with the effects of age and whether these effects must be considered in selecting normal control groups for evaluating the performance of patients. In recent therapeutic trials $[5,6]$, we have expressed the performance of patients in terms of a percentage of normal function because it is the physician's goal to return the patient to his pre-disease functional level. Thus, it is of far more importance that a patient's neurological function approach normal than it is that he double or triple some earlier functional level.

\footnotetext{
*Supported in part by NIH Special Fellow Grant 1-FO3-GM-37987-01, -02, -03,-04; The University of Michigan Institute of Science and Technology; E. I. DuPont de Nemours \& Co.; and The Upjohn Center for Clinical Pharmacology Training Group NIH 5 P 11 GM 1559 and NIH 5 TO1 HE0 5526, Bioengineering.

†This paper is a portion of a thesis submitted in partial fulfillment of the requirements for the degree of Doctor of Philosophy in Bioengineering, The University of Michigan; present address: The Bioengineering Program, The University of Texas at Arlington, Arlington, Texas 76010, U.S.A.

$\ddagger$ Chief, Neurology, VA Hospital (Wadsworth) and Professor and Vice-Chairman of Neurology, The University of California at Los Angeles, Los Angeles, California, U.S.A.

§Professor of Psychology, The University of Michigan, Ann Arbor, Michigan, U.S.A.

\|Department of Medicine, Mayo Clinic, Rochester, Minnesota, U.S.A.

**Assistant Professor of Biostatistics, The University of Iowa, School of Dentistry, lowa City, Iowa, U.S.A.

††Fcllow in Biostatistics, School of Public Health, The University of Texas at Houston, Houston, Texas, U.S.A.
}

Address requests for reprints to: Dr. A. R. Potvin, Associate Professor of Bioengineering, The Bioengineering Program, The University of Texas at Arlington, Arlington, Texas 76010, U.S.A. 
We have been concerned with the consequences of expressing the patient's performance as a percentage of normal function. The problem arises in the definition of normal function. Researchers have considered both young adult control groups (e.g. [8]) and control groups more closely matched to patients (e.g. [5]). The primary advantage of using a young adult normal control group is that it is relatively easy to recruit such subjects for evaluation, especially when the research is conducted in a university environment. The major disadvantage is that such a control group may distort the results of a clinical trial. For example, the performance level of an elderly control group may be 75 per cent that of a group of young adults. Although elderly patients in a therapeutic trial may have improved from 40 to 70 per cent of the normal function of young adults, they in fact have improved from 54 to 94 per cent of the normal function for their age group. Obviously, different conclusions might be reached with regard to the efficacy of the therapy depending upon which normal group is used as the control group.

It appears that a matched control group is superior to a young adult control group. However, there are some important disadvantages to using a matched control group. It is difficult to define what constitutes a good match; to obtain volunteers for evaluation, especially males from 25 to $65 \mathrm{yr}$ of age; and to find truly asymptomatic volunteers, especially volunteers over $45 \mathrm{yr}$ of age.

Age effects appear to be a most important criterion for matching patients to normal controls. However, an evaluation of the effects of age on performance in a large, diversified battery of tests like the QENF has not been reported. Botwinick [9] has recently reviewed the literature on the psychology of aging from 1963 to 1968 . His bibliographical search disclosed nearly 2000 references. No attempt will be made here to review this literature. A brief review of age effects and their relationship to the QENF has been made [3].

In the present study, the effects of age on performance are limited to an investigation of all the QENF tests using three normal control groups: a young adult normal subject group, a group matched to multiple sclerosis patients and a group matched to parkinsonian patients. The performance of each matched control group and each patient group ( a parkinsonian group and a multiple sclerosis group) is normalized to the performance of the young adult normal group. In addition, the performance of each patient group is normalized to that of its matched control group. From these results the relative effects of using different types of control groups in the QENF are assessed.

\section{METHODS}

Twenty asymptomatic right-handed male and twenty asymptomatic right-handed female University of Michigan undergraduate students, 18-21 yr of age (mean $=19.5$ $\mathrm{yr}$, standard deviation $=1.1 \mathrm{yr}$ ), volunteered to participate in the study. In addition, 5 male and 5 female patients having multiple sclerosis (age: mean $=35.1 \mathrm{yr}$, standard deviation $=7.9 \mathrm{yr}$ ) and their normal spouses (age : mean $=37.0 \mathrm{yr}$, standard deviation $=$ $7.2 \mathrm{yr}$ ), 5 male and 5 female parkinsonian patients (age: mean $=65.6 \mathrm{yr}$, standard deviation $=6.2 \mathrm{yr}$ ) and their normal spouses (age : mean $=60.9 \mathrm{yr}$, standard deviation 
$=10.8 \mathrm{yr}$ ) were asked by their neurologist to perform as subjects in these experiments. All subjects were told that their assistance would help our medical research program.

The selection process of patients was based on the following criteria: (1) patients must be right-handed; (2) patients must have a tremor characterized as slight, mild, or moderate in at least one upper extremity; (3) however poorly, the patients must be able to drink from a glass, use a fork, cut meat, button a garment when the buttons are visible and write; (4) multiple sclerosis patients must be $25-45 \mathrm{yr}$ of age and parkinsonian patients must be 50-75 yr of age; and (5) parkinsonian patients must be able to walk 10 steps with assistance and, as often as possible, the multiple sclerosis patients must also be able to meet this requirement. Requirements for selecting older normal subjects were that they be in the same age range as their afflicted spouses, that they be neurologically and physically normal and right-handed.

Neither the patients, who were outpatients at the University Hospital, nor the older adult normal subjects were paid a nominal fee for participating in the study. However, the university students were paid to volunteer their services. No subject was informed that he might receive special pay contingent on performance. Subjects were admitted to the study after completing a telephone questionnaire and an abbreviated neurological examination and medical history.

Three groups of subjects were selected as normal controls: a young adult control group consisting of the 40 university students, a matched control group for the parkinsonian patients consisting of the 10 spouses* of the parkinsonian patients, and a matched control group for the multiple sclerosis patients consisting of the 10 spouses* of the multiple sclerosis patients. The matched control groups were matched to the patient groups not only with respect to age but also to sex, education and socioeconomic background. The 10 parkinsonian patients and the 10 multiple sclerosis patients formed the remaining two groups used in this study.

The general experimental procedures were standardized. All subjects were instructed by the attending physician and the paramedical personnel to perform in all tests in the QENF as well as they could.

\section{RESULTS}

\section{Age effects}

Results of an analysis of variance among the three subject groups and a simple linear regression analysis with age as the independent variable for the 60 normal subjects are shown in Table 1. There are few differences in results between the significance level of the $F$ value denoting differences among the three groups in the analysis of variance and the significance level of the $t$ value denoting a slope different from zero in the regression analysis. Differences, where they exist, appear to be technical, i.e. the differences do not appear to have clinical significance.

The data were also analyzed with male and female subjects considered separately (not shown). The few differences found with the sexes considered separately and together appear to be technical. Trends for all tests were similar whether the sexes were considered separately or together.

\footnotetext{
*A few exceptions existed: one patient's brother, one patient's sister, and the parents of a MS patient were substituted when normal spouses were not available.
} 


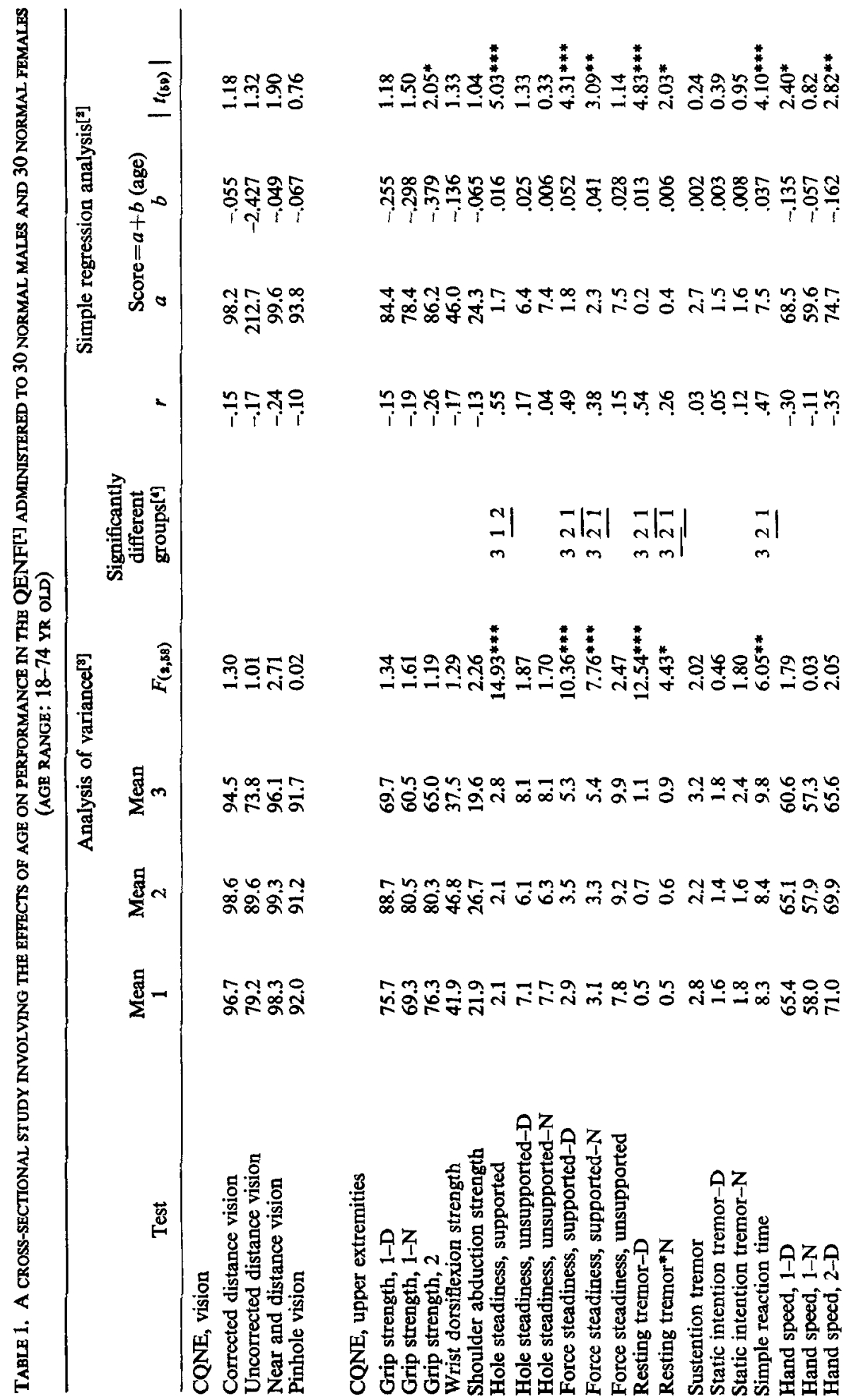




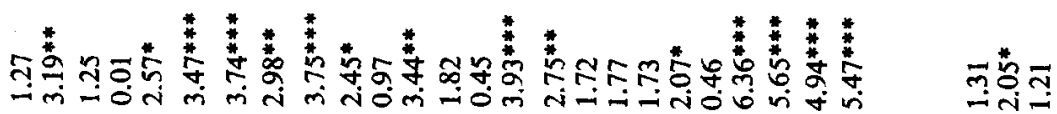

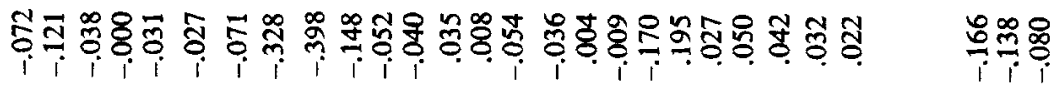

भु̆

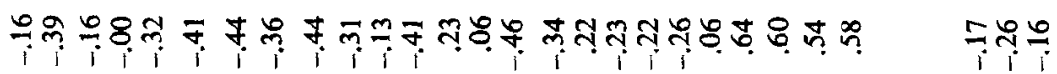

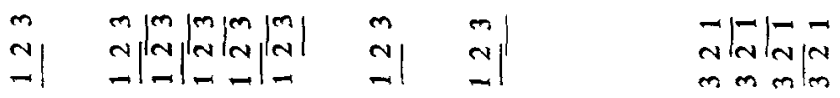

胥

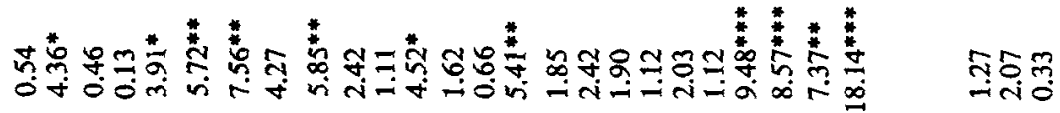

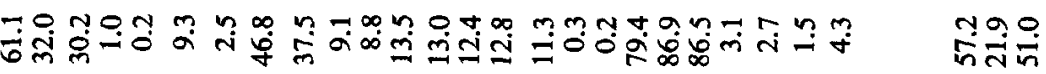

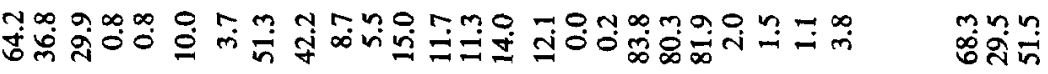

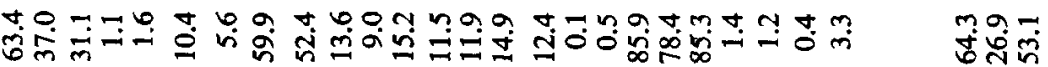

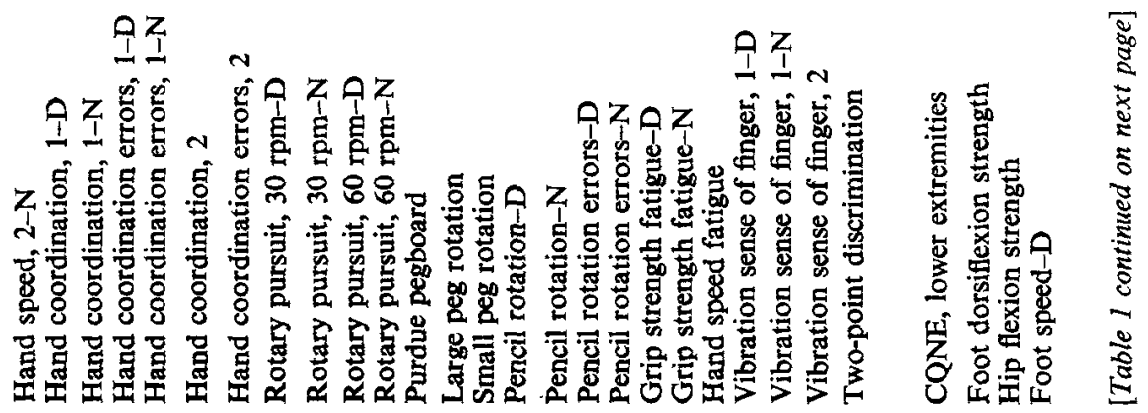




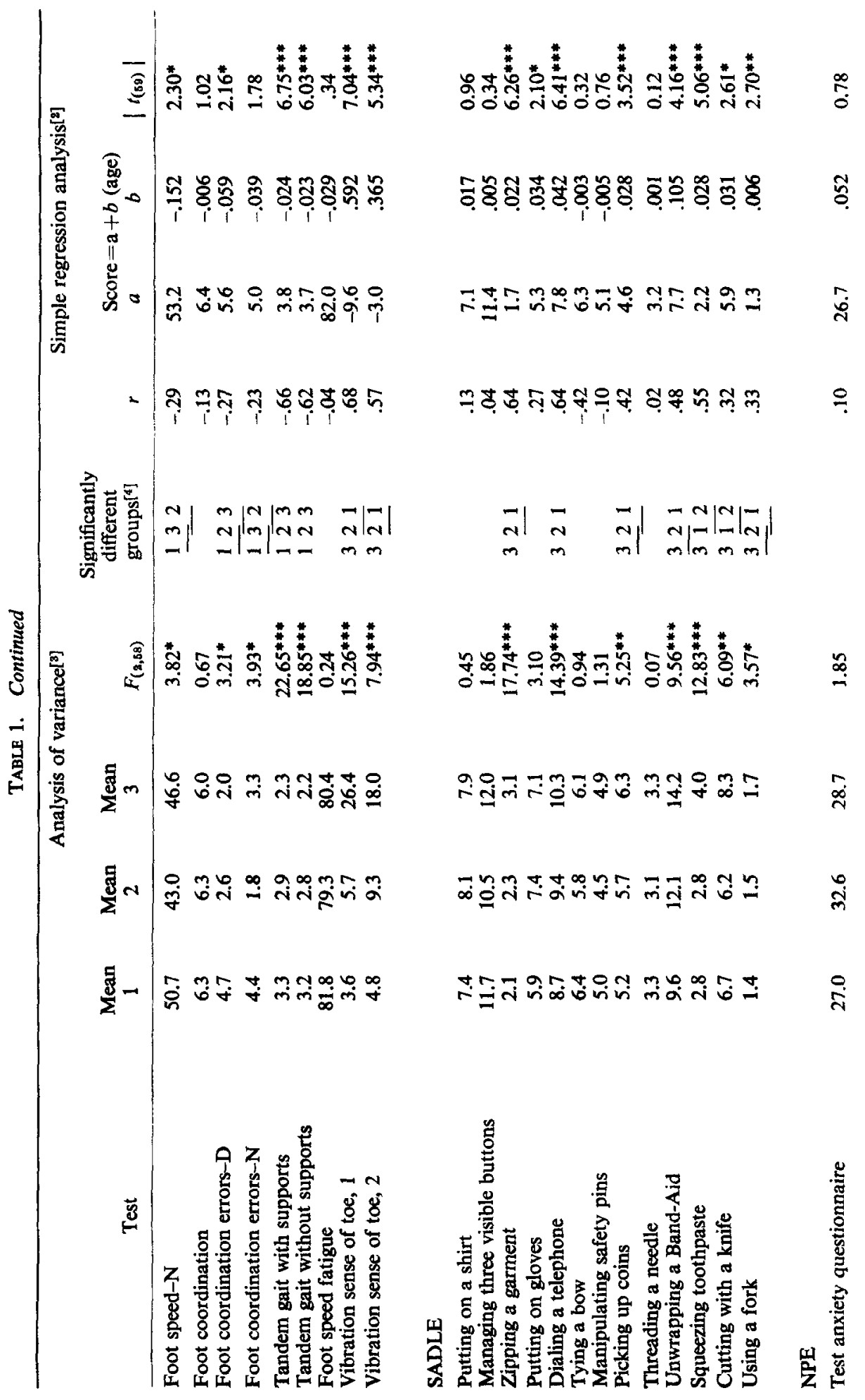




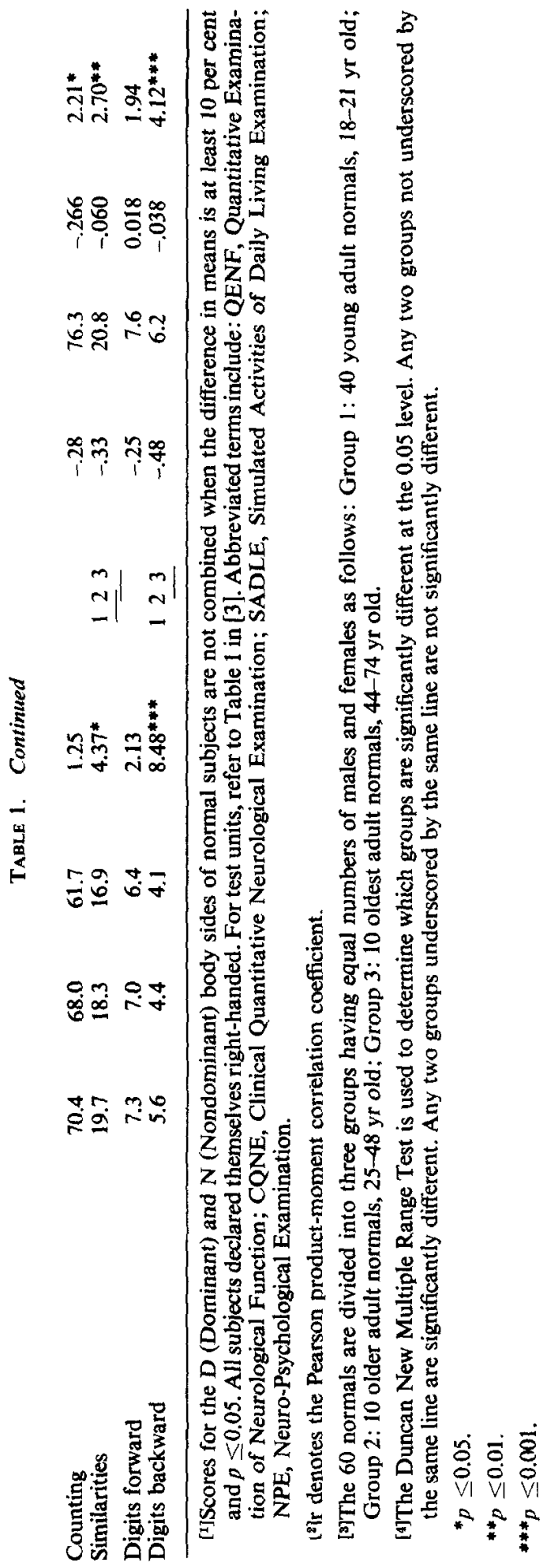




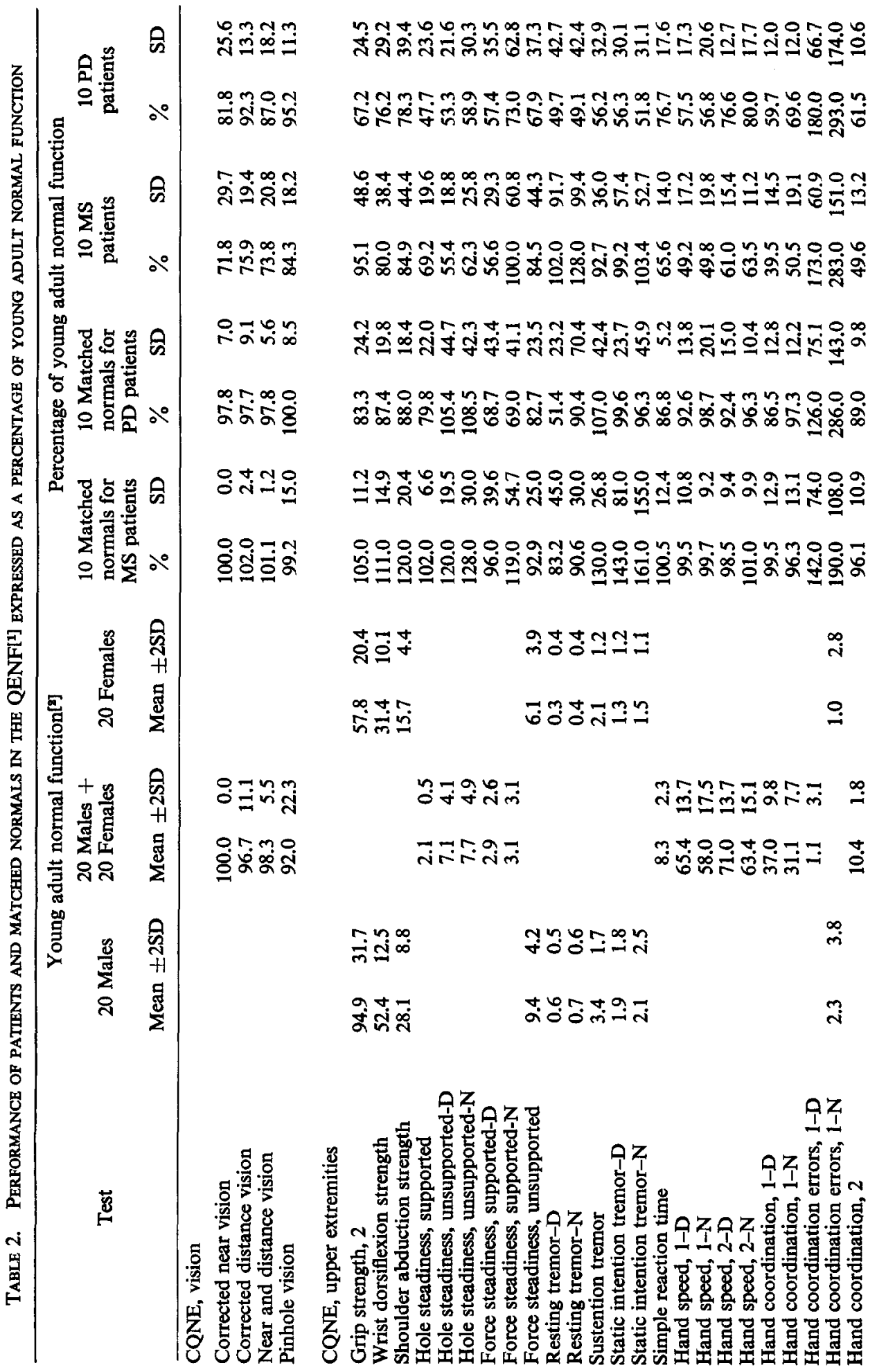




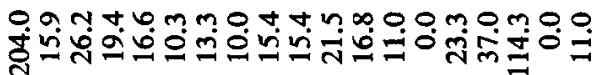

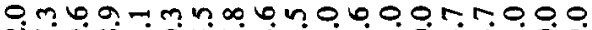

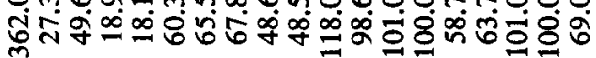

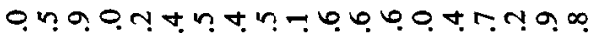

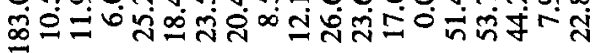

orotumentropoo tono

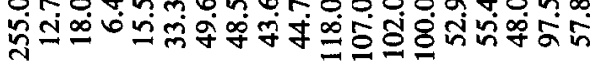

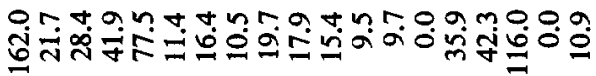

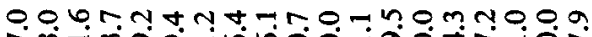

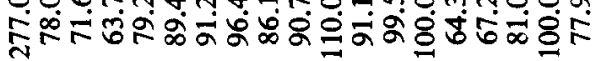

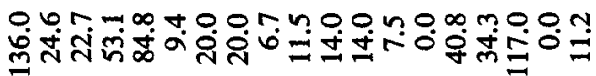
$0-15000000000000000$

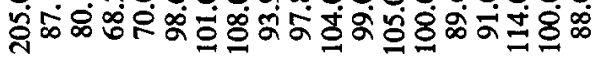

ป⿻ำ

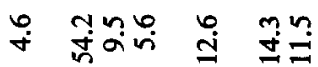

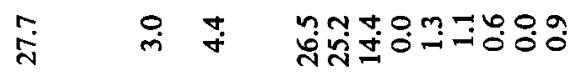

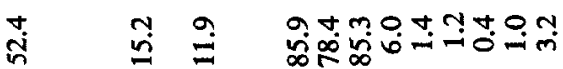

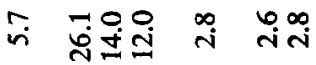

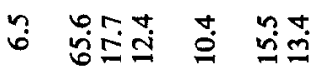

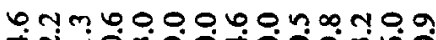

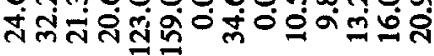

जmolooonong th

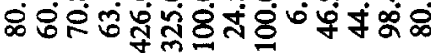

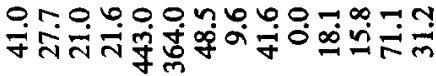

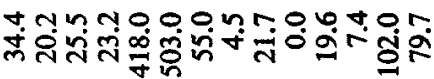

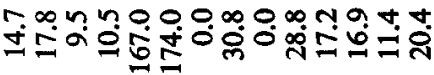

$r .0000000000001$ के

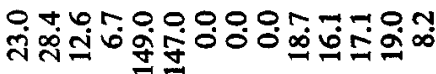

0.4 .

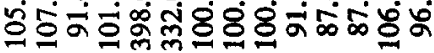

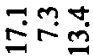

พิ่ำ

ตำ

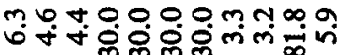

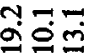

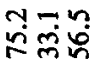
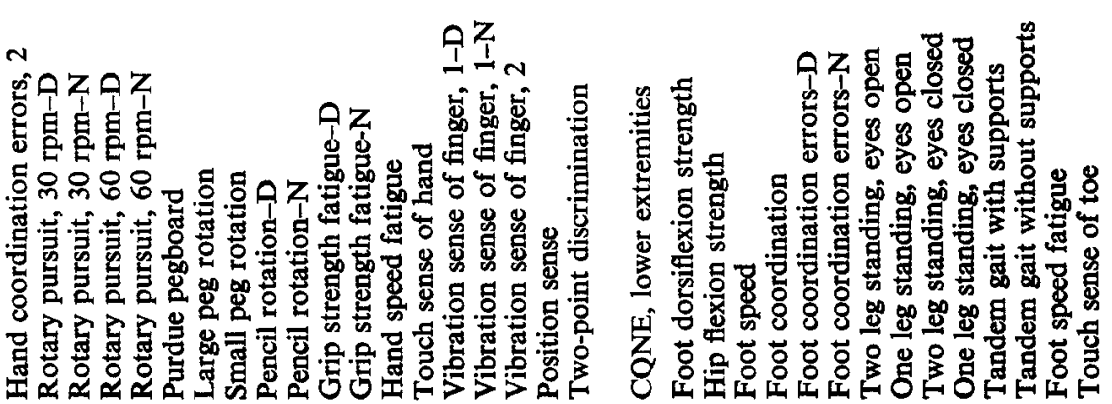


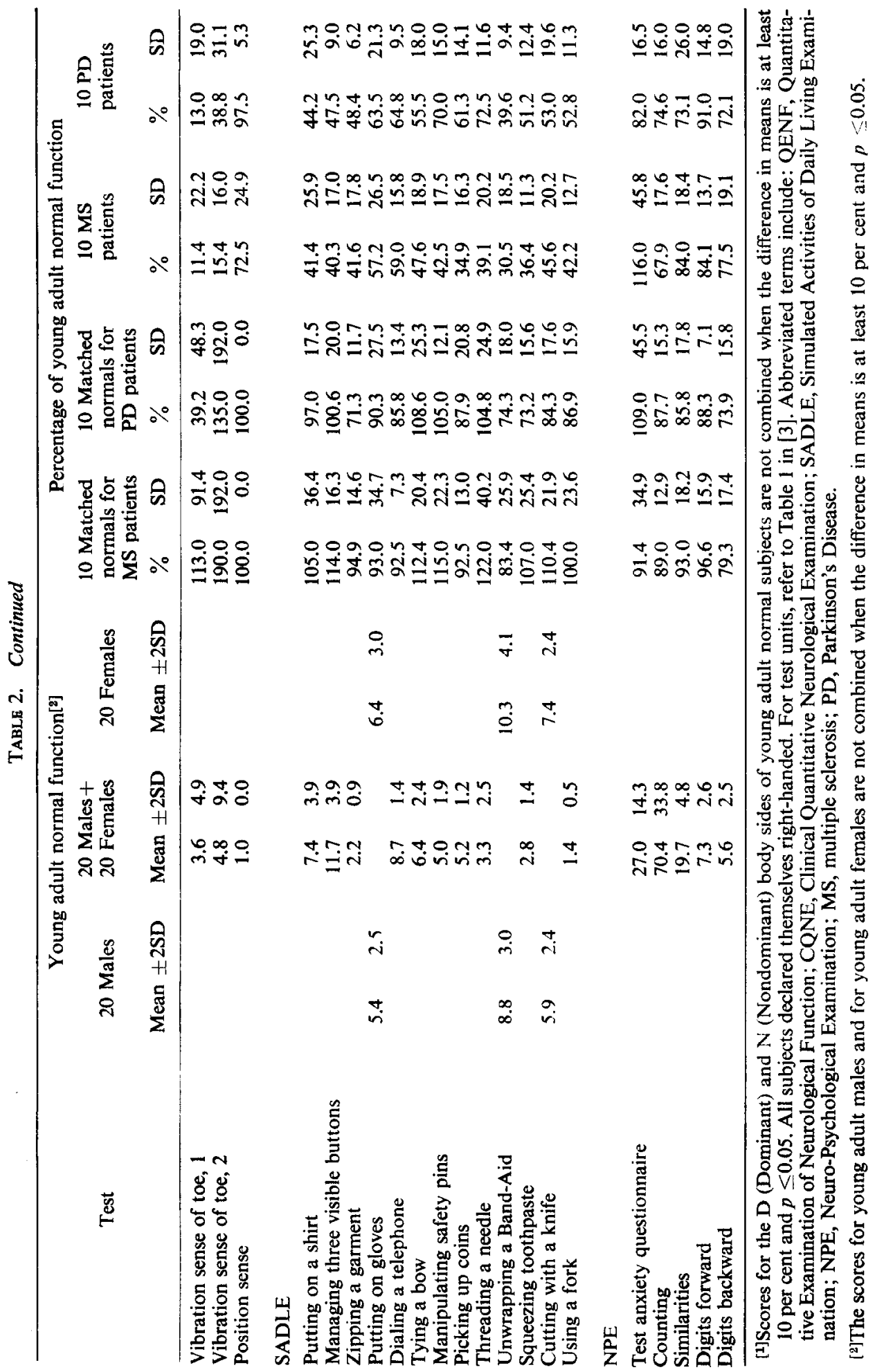


Since the experimental design and purpose for the study involves the discovery of differences between the three groups of normal subjects who span different age ranges, the results are described in terms of the analysis of variance and the Duncan New Multiple Range Test [10]. The following general observations can be made:

Although the eldest subjects tend to have poorest vision, there are no significant differences in vision among the subject groups.

There are no significant differences among the groups in the strength tests. The middle aged normal subjects are stronger than the young adult normal subjects, but not significantly so.

In the sub-battery of steadiness tests, all tests performed in a supported position indicate that steadiness supported decreases with increasing age. However, all the tests performed in an unsupported position indicate that age has no effect on steadiness unsupported.

The speed tests for the hand and foot show no significant effects of age on performance. In the Foot Speed- $N^{*}$ test, the middle aged normal subjects did not perform as well as the older aged normal subjects, perhaps a technical difference.

Tests reflecting coordination of either the upper or lower extremities show mixed results. Significant effects of age were found on tests of hand coordination 1 (for the dominant but not for the nondominant body side), hand coordination 2 , rotary pursuit (at $30 \mathrm{rpm}$ but not at $60 \mathrm{rpm}$ ), purdue pegboard, pencil rotation (for the dominant but not for the nondominant body side), tandem gait with and without supports, and for 8 of 13 tests in the Simulated Activities of Daily Living Examination (SADLE).

Performance on tests that attempt to measure fatigue is invariant with age.

Without question, the number of errors committed in coordination tests decreases with age. Significant effects are found for measures of hand coordination errors and for foot coordination errors.

Tests of vibration sense and two-point discrimination show highly significant decreases in performance with increasing age.

In the Neuro-Psychological Examination, the Similarities and Digits Backward tests show significant decreases with increasing age, while the Counting and Digits Forward tests show a nonsignificant trend in the same direction. Performance in the Test Anxiety Questionnaire is invariant with age.

\section{Per cent normal function}

The analysis of age effects indicates that performance on many tests in the QENF decreases with increasing age. As indicated earlier, the normalization technique that converts the performance of patients to a percentage of normal function should be used with caution since the normal function of subjects of various age groups differs. The present results can be reassessed by expressing the performance of the two older subject groups and the multiple sclerosis and parkinsonian patient groups as a percentage of the normal function of the young adult normal subjects (see Table 2).

For each QENF test each subject's performance was expressed as a percentage of normal function. From this, the means and standard deviations for each group of

* denotes nondominant body side and $\mathrm{N}$ denotes dominant body side. 
TABle 3. Performance of MS Patients In the QENF[1] EXPRessed as a PERCENTAGe of MATChed NORMAL FUNCTION

\begin{tabular}{|c|c|c|c|c|c|c|c|c|}
\hline \multirow[b]{3}{*}{ Test } & \multicolumn{6}{|c|}{ Matched normal function for MS patients } & \multicolumn{2}{|c|}{$\begin{array}{l}\% \text { of matched } \\
\text { normal function }\end{array}$} \\
\hline & \multicolumn{2}{|c|}{5 males } & \multicolumn{2}{|c|}{$\begin{array}{l}5 \text { males }+ \\
5 \text { females }\end{array}$} & \multicolumn{2}{|c|}{5 females } & \multicolumn{2}{|c|}{$10 \mathrm{MS}$ patients } \\
\hline & Mean & $\pm 2 \mathrm{SD}$ & Mean & $\pm 2 \mathrm{SD}$ & Mean & $\pm 2 \mathrm{SD}$ & $\%$ & SD \\
\hline \multicolumn{9}{|l|}{ CQNE, vision } \\
\hline $\begin{array}{l}\text { Corrected near vision } \\
\text { Corrected distance vision } \\
\text { Near and distance vision } \\
\text { Pinhole vision }\end{array}$ & & & $\begin{array}{r}100.0 \\
98.7 \\
99.3 \\
91.2\end{array}$ & $\begin{array}{r}0.0 \\
4.7 \\
2.3 \\
27.6\end{array}$ & & & $\begin{array}{l}71.8 \\
74.3 \\
73.1 \\
85.0\end{array}$ & $\begin{array}{l}29.7 \\
19.0 \\
20.6 \\
18.3\end{array}$ \\
\hline \multicolumn{9}{|l|}{ CQNE, upper extremities } \\
\hline $\begin{array}{l}\text { Grip strength, } 2 \\
\text { Wrist dorsiflexion strength-D } \\
\text { Wrist dorsiflexion strength-N } \\
\text { Shoulder abduction strength } \\
\text { Hole steadiness, supported } \\
\text { Hole steadiness, unsupported } \\
\text { Force steadiness, supported } \\
\text { Force steadiness, unsupported } \\
\text { Resting tremor }\end{array}$ & $\begin{array}{l}99.4 \\
63.4 \\
53.7 \\
35.2\end{array}$ & $\begin{array}{l}25.3 \\
14.2 \\
25.0 \\
13.7\end{array}$ & $\begin{array}{l}2.1 \\
6.2 \\
3.4 \\
9.2 \\
0.7\end{array}$ & $\begin{array}{l}0.3 \\
2.3 \\
2.9 \\
9.2 \\
0.6\end{array}$ & $\begin{array}{l}61.2 \\
35.0 \\
34.9 \\
18.3\end{array}$ & $\begin{array}{r}11.8 \\
8.1 \\
9.7 \\
5.4\end{array}$ & $\begin{array}{r}90.2 \\
68.2 \\
76.0 \\
71.8 \\
68.0 \\
48.2 \\
78.3 \\
100.0 \\
125.2\end{array}$ & $\begin{array}{l}45.8 \\
38.3 \\
31.2 \\
39.6 \\
19.3 \\
17.3 \\
39.6 \\
47.8 \\
64.7\end{array}$ \\
\hline $\begin{array}{l}\text { Sustention tremor } \\
\text { Static intention tremor }\end{array}$ & 2.5 & 1.0 & & & 1.8 & 0.7 & 73.1 & $\begin{array}{l}26.6 \\
45.1\end{array}$ \\
\hline $\begin{array}{l}\text { Static intention tremor } \\
\text { Simple reaction time }\end{array}$ & & & $\begin{array}{l}1.5 \\
8.4\end{array}$ & $\begin{array}{l}1.5 \\
2.2\end{array}$ & & & $\begin{array}{l}85.3 \\
66.2\end{array}$ & $\begin{array}{l}45.1 \\
14.2\end{array}$ \\
\hline Hand speed, 1-D & & & 65.1 & 14.0 & & & 49.5 & 17.3 \\
\hline Hand speed, 1-N & & & 57.9 & 10.7 & & & 49.9 & 19.9 \\
\hline Hand speed, 2 & & & 67.0 & 11.8 & & & 62.3 & 12.2 \\
\hline Hand coordination, 1-D & & & 36.8 & 9.6 & & & 39.7 & 14.6 \\
\hline Hand coordination, $1-\mathbf{N}$ & & & 29.9 & 8.1 & & & 52.5 & 19.8 \\
\hline Hand coordination errors, 1 & 1.2 & 0.9 & & & 0.4 & 2.3 & 140.0 & 86.9 \\
\hline Hand coordination, 2 & & & 10.0 & 2.3 & & & 51.7 & 13.8 \\
\hline Hand coordination errors, 2 & & & 3.7 & 3.7 & & & 162.0 & 102.7 \\
\hline Rotary pursuit, $30 \mathrm{rpm}-\mathrm{D}$ & & & 51.3 & 22.8 & & & 14.7 & 11.4 \\
\hline Rotary pursuit, $30 \mathrm{rpm}-\mathrm{N}$ & & & 42.2 & 23.8 & & & 22.3 & 14.8 \\
\hline Rotary pursuit, $60 \mathrm{rpm}-\mathrm{D}$ & & & 8.7 & 10.5 & & & 9.9 & 8.4 \\
\hline Rotary pursuit, $60 \mathrm{rpm}-\mathrm{N}$ & & & 5.5 & 10.7 & & & 21.0 & 28.6 \\
\hline Purdue pegboard & & & 14.9 & 2.8 & & & 33.8 & 18.7 \\
\hline Large peg rotation & & & 11.7 & 4.5 & & & 51.5 & 26.1 \\
\hline Small peg rotation & & & 11.3 & 4.8 & & & 46.3 & 19.5 \\
\hline Pencil rotation-D & & & 13.9 & 1.9 & & & 46.6 & 10.0 \\
\hline Pencil rotation- $N$ & & & 12.1 & 1.9 & & & 46.3 & 14.0 \\
\hline Grip strength fatigue & & & 82.1 & 18.2 & & & 111.0 & 20.5 \\
\hline Hand speed fatigue & & & 81.9 & 12.2 & & & 98.1 & 16.9 \\
\hline Touch sense of hand & & & 6.0 & 0.0 & & & 100.0 & 0.0 \\
\hline Vibration sense of finger, 1 & 1.2 & 0.5 & & & 2.2 & 1.7 & 60.8 & 52.7 \\
\hline Vibration sense of finger, 2 & & & 1.1 & 3.6 & & & 140.0 & 129.0 \\
\hline Position sense & & & 1.0 & 0.0 & & & 97.5 & 7.9 \\
\hline Two-point discrimination & & & 3.8 & 1.0 & & & 66.7 & 26.3 \\
\hline \multicolumn{9}{|l|}{ CQNE, lower extremities } \\
\hline Foot dorsiflexion strength & 83.3 & 26.7 & & & 53.3 & 30.2 & 33.1 & 41.0 \\
\hline Hip flexion strength & 39.0 & 20.4 & & & 20.1 & 10.2 & & 28.5 \\
\hline Foot specd-D & & & 51.5 & 16.1 & & & 21.2 & 20.9 \\
\hline Foot speed-N & & & 43.0 & 13.8 & & & 36.5 & 27.4 \\
\hline Foot coordination & & & 6.3 & 0.8 & & & 22.9 & 21.4 \\
\hline Foot coordination errors & & & 2.2 & 4.6 & & & 207.0 & 203.0 \\
\hline Two leg standing, eyes open & & & 30.0 & 0.0 & & & 55.0 & 48.5 \\
\hline
\end{tabular}


TABLE 3. Continued

\begin{tabular}{|c|c|c|c|c|c|c|c|c|}
\hline \multirow[b]{3}{*}{ Test } & \multicolumn{6}{|c|}{ Matched normal function for MS patients ${ }^{[2]}$} & \multicolumn{2}{|c|}{$\begin{array}{l}\% \text { of matched } \\
\text { normal function }\end{array}$} \\
\hline & \multicolumn{2}{|c|}{5 males } & \multicolumn{2}{|c|}{$\begin{array}{l}5 \text { males }+ \\
5 \text { females }\end{array}$} & \multicolumn{2}{|c|}{5 females } & \multicolumn{2}{|c|}{10 MS patients } \\
\hline & Mean & $\pm 2 \mathrm{SD}$ & Mean & $\pm 2 \mathrm{SD}$ & Mean & $\pm 2 S D$ & $\%$ & SD \\
\hline One leg standing, eyes open & & & 30.0 & 0.0 & & & 4.5 & 9.6 \\
\hline Two leg standing, eyes closed & & & 30.0 & 0.0 & & & 21.7 & 41.6 \\
\hline One leg standing, eyes closed & & & 27.6 & 11.3 & & & 0.0 & 0.0 \\
\hline Tandem gait with supports & & & 2.9 & 1.1 & & & 22.4 & 20.7 \\
\hline Tandem gait without supports & & & 2.8 & 1.1 & & & 8.5 & 38.0 \\
\hline Foot speed fatigue & & & 79.3 & 32.6 & & & 121.2 & 56.4 \\
\hline Touch sense of toe & & & 5.7 & 1.0 & & & 82.5 & 32.3 \\
\hline Vibration sense of toe, 1 & & & 5.7 & 10.5 & & & 18.0 & 35.2 \\
\hline Vibration sense of toe, 2 & & & 9.3 & 25.5 & & & 29.5 & 30.7 \\
\hline Position sense & & & 1.0 & 0.0 & & & 72,5 & 24.9 \\
\hline \multicolumn{9}{|l|}{ SADLE } \\
\hline Putting on a shirt & & & 8.1 & 7.0 & & & 45.1 & 28.2 \\
\hline Managing three visible buttons & 11.4 & 3.0 & & & 9.6 & 2.1 & 36.3 & 15.4 \\
\hline Zipping a garment & & & 2.3 & 0.8 & & & 44.9 & 19.1 \\
\hline Putting on gloves & & & 7.4 & 6.6 & & & 72.1 & 32.6 \\
\hline Dialing a telephone & & & 9.4 & 1.4 & & & 64.1 & 17.2 \\
\hline Tying a bow & & & 5.8 & 1.9 & & & 43.5 & 17.3 \\
\hline Manipulating safety pins & 5.3 & 0.8 & & & 3.8 & 0.7 & 38.6 & 17.5 \\
\hline Picking up coins & & & 5.7 & 1.7 & & & 38.4 & 17.9 \\
\hline Threading a needle & & & 3.1 & 3.3 & & & 37,4 & 19.3 \\
\hline Unwrapping a Band-Aid & & & 12.1 & 5.3 & & & 39.0 & 23.0 \\
\hline Squeezing toothpaste & & & 2.8 & 1.2 & & & 35.5 & 11.0 \\
\hline Cutting with a knife & & & 6.2 & 1.7 & & & 41.7 & 15.8 \\
\hline Using a fork & & & 1.5 & 0.7 & & & 44.2 & 13.4 \\
\hline \multicolumn{9}{|l|}{ NPE } \\
\hline Test anxiety questionnaire & & & 32.6 & 18.1 & & & 140.0 & 55.3 \\
\hline Counting & & & 68.0 & 27.1 & & & 70.3 & 18.2 \\
\hline Similarities & & & 18.3 & 7.2 & & & 90.2 & 19.8 \\
\hline Digits forward & & & 7.0 & 2.3 & & & 87.1 & 14.2 \\
\hline Digits backward & 3.8 & 0.9 & & & 5.0 & 2.0 & 98.6 & 22.9 \\
\hline
\end{tabular}

[1]Scores for the D (Dominant) and N (Nondominant) body sides of matched normals for the MS patients are not combined when the difference in means is at least 10 per cent and $p \leq 0.05$. All subjects declared themselves right-handed. For test units, refer to Table 1 in [3]. Abbreviated terms include: QENF, Quantitative Examination of Neurological Function; CQNE, Clinical Quantitative Neurological Examination; SADLE, Simulated Activities of Daily Living Examination; NPE, Neuro-Pyschological Examination; MS, multiple sclerosis.

subjects were obtained. Results are shown in Table 2 . Because performance by young adult male subjects can be significantly different on some tests from performance by young adult normal female subjects [3], the percentage of normal function for each of the four groups shown in Table 2 was obtained separately for each sex on those tests and then combined.

From Table 2, the following observations are made:

The performance of the 10 normals matched to the multiple sclerosis patients does not differ appreciably from that of young adult normal subjects. 
TABle 4. Performance of PD PATIENTS IN THE QENF[1] eXPRessed as A PERCENTAGe OF MATChed NORMAL FUNCTION

\begin{tabular}{|c|c|c|c|c|c|c|c|c|}
\hline \multirow[b]{3}{*}{ Test } & \multicolumn{6}{|c|}{ Matched normal function for PD patients } & \multirow{2}{*}{\multicolumn{2}{|c|}{$\begin{array}{l}\% \text { of matched } \\
\text { normal function } \\
10 \text { PD patients }\end{array}$}} \\
\hline & \multicolumn{2}{|c|}{5 males } & \multicolumn{2}{|c|}{$\begin{array}{l}5 \text { males } 1 \\
5 \text { females }\end{array}$} & \multicolumn{2}{|c|}{5 females } & & \\
\hline & Mean & $\pm 2 \mathrm{SD}$ & Mean & $\pm 2 \mathrm{SD}$ & Mean & $\pm 2 \mathrm{SD}$ & $\%$ & SD \\
\hline \multicolumn{9}{|l|}{ CQNE, vision } \\
\hline Corrected near vision & & & 97.8 & 13.9 & & & 83.7 & 26.2 \\
\hline Corrected distance vision & & & 94.4 & 17.6 & & & 94.5 & 13.6 \\
\hline Near and distance vision & & & 96.1 & 11.1 & & & 89.0 & 18.7 \\
\hline Pinhole vision & & & 91.7 & 15.6 & & & 95.4 & 11.3 \\
\hline \multicolumn{9}{|l|}{ CQNE, upper extremities } \\
\hline Grip strength, 2 & 86.1 & 47.3 & & & 43.9 & 27.3 & 82.2 & 33.0 \\
\hline Wrist dorsiffexion strength & 50.0 & 17.2 & & & 24.9 & 13.4 & 89.9 & 38.0 \\
\hline Shoulder abduction strength & 26.0 & 7.5 & & & 13.1 & 7.3 & 90.5 & 48.4 \\
\hline Hole steadiness, supported & & & 2.8 & 1.5 & & & 64.0 & 31.6 \\
\hline Hole steadiness, unsupported & & & 8.1 & 6.6 & & & 60.0 & 26.6 \\
\hline Force steadiness, supported & 6.6 & 2.6 & & & 4.1 & 3.4 & 89.5 & 59.8 \\
\hline $\begin{array}{l}\text { Force steadiness, } \\
\text { unsupported-D }\end{array}$ & & & 10.5 & 5.4 & & & 040 & 71 \\
\hline Force steadiness, & & & 10.0 & & & & 104.0 & 11.1 \\
\hline unsupported-N & 11.4 & 6.8 & & & 7.3 & 3.8 & 86.3 & 49.0 \\
\hline Resting tremor & & & 1.0 & 0.9 & & & 117.0 & 120.0 \\
\hline Sustention tremor & & & 3.2 & 4.3 & & & 73.8 & 50.2 \\
\hline Static intention tremor & & & 2.1 & 1.9 & & & 67.0 & 46.3 \\
\hline Simple reaction time & & & 9.8 & 2.5 & & & 89.9 & 20.6 \\
\hline Hand speed, 1 & & & 59.0 & 18.9 & & & 59.9 & 17.7 \\
\hline Hand speed, 2 & & & 63.3 & 16.8 & & & 83.0 & 15.0 \\
\hline Hand coordination, 1 & & & 31.1 & 8.3 & & & 70.3 & 13.0 \\
\hline Hand coordination errors, 1-D & 1.8 & 0.9 & & & 0.2 & 0.9 & 194.0 & 175.0 \\
\hline Hand coordination errors, $1-\mathrm{N}$ & & & 0.2 & 1.3 & & & 34.3 & 12.7 \\
\hline Hand coordination, 2 & & & 9.3 & 2.0 & & & 69.1 & 12.0 \\
\hline Hand coordination errors, 2 & & & 2.6 & 2.7 & & & 165.3 & 86.9 \\
\hline Rotary pursuit, $30 \mathrm{rpm}-\mathrm{D}$ & & & 46.8 & 27.9 & & & 35.2 & 20.7 \\
\hline Rotary pursuit, $30 \mathrm{rpm}-\mathrm{N}$ & & & 37.5 & 29.8 & & & 69.2 & 36.6 \\
\hline Rotary pursuit, $60 \mathrm{rpm}$ & 14.5 & 17.4 & & & 3.4 & 4.8 & 31.9 & 29.1 \\
\hline Purdue pegboard & & & 13.6 & 3.4 & & & 67.5 & 11.6 \\
\hline Large peg rotation & & & 13.0 & 5.9 & & & 73.8 & 10.2 \\
\hline Small peg rotation & & & 12.4 & 2.7 & & & 71.0 & 10.4 \\
\hline Pencil rotation-D & & & 12.8 & 6.3 & & & 56.0 & 17.3 \\
\hline Pencil rotation- $\mathbf{N}$ & & & 11.3 & 5.0 & & & 53.5 & 18.1 \\
\hline Grip strength fatigue & & & 83.1 & 14.8 & & & 108.0 & 15.4 \\
\hline Hand speed fatigue & & & 86.5 & 18.7 & & & 103.0 & 11.2 \\
\hline Touch sense of hand & & & 6.0 & 0.0 & & & 100.0 & 0.0 \\
\hline Vibration sense of finger, 1 & & & 2.9 & 4.2 & & & 132.0 & 61.5 \\
\hline Vibration sense of finger, 2 & & & 1.5 & 2.3 & & & 355.0 & 361.0 \\
\hline Position sense & & & 1.0 & 0.0 & & & 100.0 & 0.0 \\
\hline Two-point discrimination & & & 4.2 & 1.3 & & & 90.3 & 14.3 \\
\hline \multicolumn{9}{|l|}{ CQNE, lower extremities } \\
\hline Foot dorsiflexion strength & 71.4 & 23.4 & & & 42.9 & 11.2 & 93.4 & 32.5 \\
\hline Hip flexion strength & 27.8 & 10.3 & & & 16.1 & 8.8 & 74.9 & 41.7 \\
\hline Foot speed & 54.5 & 11.6 & & & 43.1 & 8.4 & & 23.7 \\
\hline Foot coordination & & & 6.0 & 1.3 & & & 66.2 & 21.4 \\
\hline Foot coordination erro & & & 2.7 & 2.5 & & & 204.9 & 87.8 \\
\hline Two leg standing, eyes open & & & 30.0 & 0.0 & & & 100.0 & 0.0 \\
\hline
\end{tabular}


TABLE 4. Continued

\begin{tabular}{|c|c|c|c|c|c|c|c|c|}
\hline & & & & & & & & \\
\hline One leg standing, eyes open & & & 25.2 & 18.5 & & & 29.2 & 41.2 \\
\hline Two leg standing, eyes closed & & & 30.0 & 0.0 & & & 100.0 & 0.0 \\
\hline One leg standing, eyes closed & 16.4 & 18.6 & & & 5.7 & 6.5 & 21.6 & 35.7 \\
\hline Tandem gait with supports & & & 2.3 & 1.1 & & & 68.4 & 14.3 \\
\hline Tandem gait without supports & & & 2.2 & 1.1 & & & 63.8 & 19.1 \\
\hline Foot speed fatigue & & & 80.4 & 18.9 & & & 96.7 & 15.7 \\
\hline Touch sense of toe & & & 5.4 & 2.4 & & & 88.8 & 23.0 \\
\hline Vibration sense of toe, 1 & & & 26.4 & 57.3 & & & 94.9 & 138.0 \\
\hline Vibration sense of toe, 2 & & & 18.0 & 34.7 & & & 229.0 & 292.0 \\
\hline Position sense & & & 1.0 & 0.0 & & & 97.5 & 5.3 \\
\hline \multicolumn{9}{|l|}{ SADLE } \\
\hline Putting on a shirt & & & 7.9 & 2.8 & & & 46.9 & 26.8 \\
\hline Managing three visible buttons & & & 12.0 & 4.0 & & & 48.6 & 9.3 \\
\hline Zipping a garment & & & 3.1 & 1.1 & & & 69.7 & 8.9 \\
\hline Putting on gloves & 5.1 & 2.3 & & & 9.2 & 3.7 & 79.0 & 38.1 \\
\hline Dialing a telephone & 9.3 & 2.6 & & & 11.3 & 2.4 & 77.8 & 17.7 \\
\hline Tying a bow & & & 6.1 & 2.5 & & & 53.4 & 17.3 \\
\hline Manipulating safety pins & & & 4.8 & 1.1 & & & 67.5 & 14.5 \\
\hline Picking up coins & & & 6.3 & 4.3 & & & 75.0 & 17.3 \\
\hline Threading a needle & & & 3.3 & 2.0 & & & 73.8 & 11.8 \\
\hline Unwrapping a Band-Aid & & & 14.1 & 12.7 & & & 58.7 & 12.9 \\
\hline Squeezing toothpaste & & & 4.0 & 1.7 & & & 72.8 & 17.6 \\
\hline Cutting with a knife & & & 8.2 & 4.2 & & & 65.4 & 22.7 \\
\hline Using a fork & 1.5 & 0.3 & & & 1.9 & 0.6 & 63.0 & 16.9 \\
\hline \multicolumn{9}{|l|}{ NPE } \\
\hline Test anxiety questionnaire & & & 28.7 & 22.7 & & & 87.2 & 17.5 \\
\hline Counting & 70.2 & 15.3 & & & 53.2 & 9.6 & 87.4 & 25.8 \\
\hline Similarities & & & 16.9 & 7.0 & & & 85.2 & 30.3 \\
\hline Digits forward & & & 6.4 & 1.0 & & & 103.1 & 16.8 \\
\hline Digits backward & & & 4.1 & 1.8 & & & 97.6 & 25.7 \\
\hline
\end{tabular}

[1]Scores for the D (Dominant) and N (Nondominant) body sides of matched normals for the PD patients are not combined when the difference in means is at least 10 per cent and $p \leq 0.05$. All subjects declared themselves right-handed. For test units, refer to Table 1 in [3]. Abbreviated terms include: QENF, Quantitative Examination of Neurological Function; CQNE, Clinical Quantitative Neurological Examination; SADLE, Simulated Activities of Daily Living Examination; NPE, Neuro-Psychological Examination; PD, Parkinson's Disease.

The performance of the 10 normals matched to the parkinsonian patients is less than that for the two younger normal subject groups on many tests.

The performance of the two patient groups is considerably less than that of any normal subject group.

Tests that have been shown to have significant effects of age on performance (Table 1) are reasonably evident from examination of Table 2.

Tests that have shown a high variability in performance for patients [3] also indicate a lower percentage of normal function.

The older normal subject groups and the patient groups make fewer errors than young adult normal subjects on tests that involve both speed and accuracy.

Tables 3 and 4 show the performance of the multiple sclerosis and parkinsonian patients as a percentage of normal function based upon the normal groups which 
were specifically matched to the patient groups. The differences in percentage of matched normal function for multiple sclerosis patients between Tables 2 and 3 are small. Far greater differences, however, are easily observable for Parkinson's disease patients between Tables 2 and 4 .

\section{Composite scores}

The above results can be seen more easily from composite scores of a selected number of CQNE and SADLE tests (see Table 5). The performance of multiple sclerosis patients on both the CQNE and SADLE composites expressed as a percentage of normal function of young adult normal subjects or matched normal subjects differs by less than 2 per cent. However, the same analysis for the parkinsonian patients indicates a difference exceeding 10 per cent.

Tables 2, 3 and 4 contain much data, making visual analysis difficult. Composite scores can be used to combine data or related tests to meaningfully reduce data for easier analysis. Figure 1 illustrates the method. The data from tests measuring the same primary category of neurological function have been combined and averaged for multiple sclerosis and parkinsonian patients from Tables 3 and 4, respectively. The categories affected by the disease can readily be determined for both the multiple sclerosis and parkinsonian patients. Compared to other data reduction methods reviewed by Potvin [3], this method appears to provide more meaningful indices of neurological function.

\section{DISCUSSION}

The results of age on performance indicates that the middle aged subjects are stronger than the young subjects. Although the trend may result from differences other

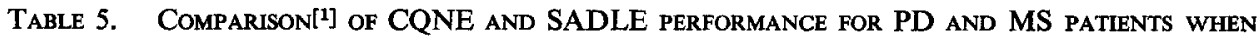
THEIR PERFORMANCE IS EXPRESSED AS A PERCENTAGE OF NORMAL FUNCTION

\begin{tabular}{cccccc}
\hline Patients & \multicolumn{1}{c}{ Normal subject group } & $\begin{array}{c}\text { Mean \% } \\
\text { CQNE[ }\end{array}$ & $\begin{array}{c}\text { Mean } \% \\
\text { SADLE[ }\end{array}$ & $\begin{array}{c}\% \\
\left.\text { Diff. } .^{4}\right]\end{array}$ & $\begin{array}{c}\text { Paired }|t| \\
\text { value }\end{array}$ \\
\hline 10 PD & 40 young adult normals & 59.2 & 55.7 & $4.8 \dagger$ & 1.82 \\
$10 \mathrm{PD}$ & 10 matched normals & 72.2 & 65.5 & $7.8 \dagger$ & $2.19^{*}$ \\
10 MS & 40 young adult normals & 46.2 & 43.0 & $7.8 \dagger$ & 1.73 \\
10 MS & 10 matched normals & 44.6 & 44.7 & 0.7 & 0.08 \\
\hline
\end{tabular}

[1]All subjects declared themselves right-handed. Abbreviated terms include: CQNE, Clinical Quantitative Neurological Examination; SADLE, Simulated Activities of Daily Living Examination; PD, Parkinson's Disease; MS, multiple sclerosis.

${ }^{[2]}$ CQNE tests include: Force steadiness, supported-D, N; Force steadiness, unsupported; Simple reaction time; Hand speed, 2-D, N; Hand coordination, 1-D, N; Hand coordination, 2; Rotary pursuit, $60 \mathrm{rpm}-\mathrm{D}, \mathrm{N}$; Purdue pegboard; Small peg rotation; Pencil rotation-D, N; Foot speed; Foot coordination; Tandem gait with supports.

[3]SADLE tests include: Putting on a shirt; Managing three visible buttons; Zipping a garment; Putting on gloves; Dialing a telephone; Tying a bow; Manipulating safety pins; Picking up coins; Threading a needle; Unwrapping a Band-Aid; Squeezing toothpaste; Cutting with a knife; Using a fork.

$\left.{ }^{4}\right]$ Per cent difference $=100 / n \mid \Sigma[(\%$ SADLE - \% CQNE $) /(\%$ CQNE $)] \mid$, where $n=10$, the number of patients.

${ }^{*} p \leq 0.05$.

†Indicates better performance on CQNE than on SADLE. 


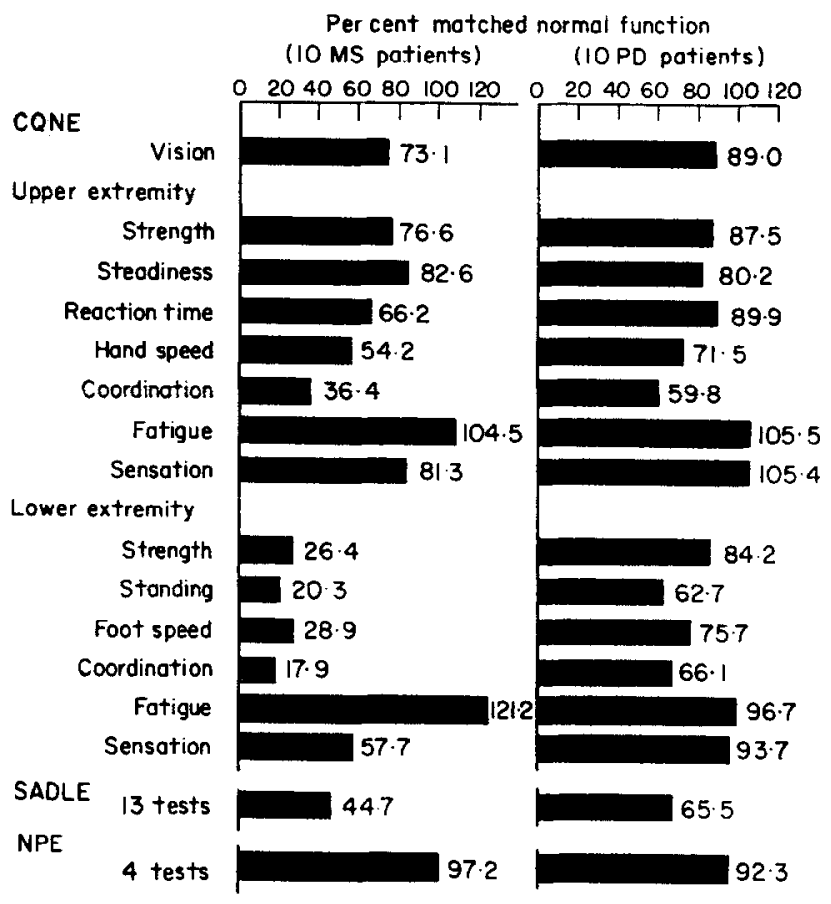

Fig. 1. Comparison of the performance of MS and PD patients when performance is expressed in functional categories as a percentage of matched normal function (refer to text and Table 5).

than age (such as socioeconomic differences), others have also reported a similar trend [11-13].

The differences in results found in the sub-battery of steadiness tests between tests performed in the supported and in the unsupported position are not in agreement with Albers in an earlier study $[14,15]$. His sampleincluded a group of 20 right-handed young adult normal subjects (mean age $=22.4 \mathrm{yr}$, standard deviation $=2.7 \mathrm{yr}$ ) and a group of 7 right-handed older adult normal subjects (mean age $=56.7 \mathrm{yr}$, standard deviation $=3.2 \mathrm{yr}$ ). With a larger sample group, Albers might have found significant differences.

From the results shown in Table 1, it appears that only tests requiring fine skilled movements primarily with the dominant hand show significant deterioration of performance with increasing age. Examination of the tests in the SADLE reveals that performance on tests requiring two hands, such as Putting on a Shirt, Managing Three Visible Buttons, Putting on Gloves, Tying a Bow, Manipulating Safety Pins and Threading a Needle, is invariant with age. On the remaining SADLE tests requiring skilled movements primarily with the dominant hand, performance deteriorates significantly with increasing age.

The decrease in the number of errors committed in the coordination tasks as age increases is in agreement with Welford's results [16]. He found that older subjects, when given the opportunity to shift between speed and accuracy, tend toward increased accuracy. He implied a biological reason for this shift - as people age they become increasingly careful in their habits to avoid injury. 
Comparisons of age results in the Neuro-Psychological Examination are confounded by the higher educational level achieved by the young adult normal subjects. The results obtained may nonetheless reflect differences that can be attributed to age.

Where age differences in performance are significant, the Duncan New Multiple Range Test indicates that the performance of the group of oldest subjects is significantly worse than for both younger groups. The two younger groups are found to be significantly different in their performance for only two tests, Digits Backward and Vibration Sense of Finger 2. As mentioned above, the younger group's superior performance in the Digits Backward test may be attributed to differences other than age among the populations sampled. The difference in the vibration sense test may be technical; the difference is not found for the more reliable [3] Vibration Sense of Finger 1 test. This general finding for the two younger groups indicates that performance in tests that span a broad range of human function does not change appreciably, at least up to the mid-forties, in agreement with the results of many other researchers (e.g. $[9,16])$.

Differences in performance between the young adult normal group and the two older adult normal groups can conceivably be attributed to differences in motivation. The two older adult normal groups were family members of patients and might be motivated to perform at a higher level than the paid non-emotionally involved young adult control group. However, a second study performed with these same subject groups showed that this hypothesis is false: all subject groups are uniformly motivated [17].

When the performance of patients is expressed as a percentage of matched normal function, only slight differences are seen for the middle-aged multiple sclerosis patients when compared to the same performance expressed as a percentage of young adult normal function. For the elderly parkinsonian patients, however, the net result of using young adult normal controls (instead of matched controls) is to decrease the apparent function of the patients. In a therapeutic trial, this procedure could conceivably lead to erroneous conclusions, as discussed earlier.

\section{SUMMARY}

Forty young adult normal subjects, 10 Parkinson's disease patients and their 10 matched normal subjects, and 10 multiple sclerosis patients and their 10 matched normal subjects were evaluated in the Quantitative Examination of Neurological Function to determine age effects and the importance of selecting closely matched normal control groups for assessing the performance of patients. Where there are significant differences among the three normal subject groups, it is the oldest normal subject group that differs from the two younger subject groups. Significant decreases in performance with increasing age were found for the steadiness tests performed in the supported position, the sensation tests, two or five tests in the Neuro-Psychological Examination and tests requiring fine skilled movements primarily with the dominant hand. It was found that older subjects made fewer errors in coordinated tasks.

A normalization technique, expressing performance as a percentage of normal function, was introduced. A method was developed to provide quantitative and meaningful indices of neurological function. The measure is obtained by averaging the percentage of normal function scores over several tests that belong to a primary category of neurological function. 
Young aduit normal subjects do not perform significantly better than normal subjects in the age range of multiple sclerosis patients; however, young adult normal subjects do perform significantly better than normal subjects in the age range of Parkinson's disease patients, especially on tasks requiring fine skilled movements of the dominant hand and coordinated activities of the lower extremities. These results indicate that the performance of multiple sclerosis patients can be expressed as a percentage of the function of either age-matched normal controls or young adult normal controls. However, the performance of Parkinson's disease patients should be expressed only as a percentage of the function of age-matched normal controls.

Acknowledgements-The authors acknowledge the data collection assistance of Mrs. C. Kazmierczak, R. P. T., and Mrs. J. S. Dailey, O.T.R.; the technical assistance of Mr. R. F. Stribley; Dr. E. A. Carr and his staff for the use of the Upjohn Center facilities; and Dr. J. E. Walker for conducting neurological examinations on the patients and matched controls.

\section{REFERENCES}

1. Tourtellotte WW, Haerer AF, Simpson JF et al: Quantitative clinical neurological testing-I: a study of a battery of tests designed to evaluate in part the neurological function of patients with multiple sclerosis and its use in a therapeutic trial. NY Acad Sci 122: 480-505, 1965

2. Kuzma JW, Tourtellotte WW, Remington RD: Quantitative clinical neurological testing-II: some statistical considerations of a battery of tests. J Chron Dis 18: 303-311, 1965

3. Potvin AR. The effects of age, motivation, and learning on performance in the quantitative examination of neurological function. Doc. diss., The Univ. of Mich., Ann Arbor, 1971

4. Potvin AR, Tourtellotte WW, Dailey JS et al: Simulated activities of daily living examination. Arch Phys Med Rehab 53: 476-487, 1972

5. Walker JE, Albers JW, Tourtellotte WW et al: A qualitative and quantitative evaluation of amantadine in the treatment of Parkinson's Disease. J Chron Dis 25: 149-182, 1972

6. Walker JE, Potvin AR, Tourtellotte WW et al: Amantadine and levodopa in the treatment of Parkinson's Disease. Clin Pharm Therap 13: 28-36, 1972

7. Rose AS, Kuzma JW, Kurtzke JF et al: Cooperative study in the evaluation of therapy in multiple sclerosis: ACTH vs. placebo. Final report. Neurology 20: 1-59, 1970

Addendum in Wolfgram F, Ellison JG et al (eds): Multiple Sclerosis. Immunology, Virology and Ultrastructure. Academic Press: New York, 1972, pp 527, 528

8. Henderson WG: Application of some statistical methods including factor analysis to a battery of clinical quantitative neurological tests for evaluating disability in multiple sclerosis. Doc. diss., The Univ, of Mich., Ann Arbor, 1970

9. Botwinick J: Geropsychology. Ann Rev Psychol 21 : 239-273, 1970

10. Steel RGD, Torrie JH: Principles and Procedures of Statistics with Special Reference to the Biological Sciences. McGraw-Hill: New York, 1960

11. Hunsicker R, Greey G: Studies in human strength. Res Quart 28: 109-122, 1957

12. Nementhi CE: An evaluation of hand grip in industry. Ind Med Surg 21: 65-66, 1952

13. Fisher MB, Birren JE: Age and strength. J Appl Psychol 31: 490-497, 1947

14. Albers JW: A quantitative investigation of tremor in asymptomatic and pathological subjects. Doc. diss., The Univ. of Mich., Ann Arbor, 1970

15. Albers, JW, Potvin AR, Tourtellotte WW et al: Quantification of hand tremor in the clinical neurological examination. IEEE Trans on Biomed Engr 27-37, 1973

16. Welford AT: Ageing and Human Skill. Oxford University Press: London, 1958

17. Potvin AR, Tourtellotte WW Pew RW et al: Motivation and learning in the quantitative examination of neurological function. Arch Phys Med Rehab 54: 432-440, 1973 